\title{
Genetic Evaluation of Sires and Environmental Factors Influencing Best Racing Times of Thoroughbred Horses in Japan
}

\author{
Yasuyoshi MORITSU ${ }^{1}$ *, Hiromi FUNAKOSHI ${ }^{2}$ and Shun ICHIKAWA ${ }^{1}$ \\ ${ }^{1}$ Laboratory of Animal Breeding, Department of Dairy Science, Hokkaido College of Arts and Sciences, \\ Ebetsu, Hokkaido 069, and ${ }^{2}$ Laboratory of Animal Breeding, Department of Dairy Science, Rakuno \\ Gakuen University, Ebetsu, Hokkaido 069, Japan
}

\begin{abstract}
The sire effect and the fixed effects of sex, training center, type of course, specific racetrack, horse age and track condition were evaluated regarding best racing times of thoroughbred horses. The records of best racing times at the Japan Racing Association were collected from the electronic racing book. The data set was edited so that each sire was required to have at least twenty progeny in the racing distances of $1200 \mathrm{~m}$ and $1800 \mathrm{~m}$. The total numbers of sires and progeny were 34 and 1486 for $1200 \mathrm{~m}$ and 34 and 1520 for $1800 \mathrm{~m}$. First, the least-squares analysis of variance was carried out by using the linear model which included the sire effect and the six fixed effects. Second, heritabilities for best racing times were calculated, and additionally sire evaluations were carried out by using the sire model of the BLUP method.

As a result of analysis of variance, almost all effects included in the linear model were significant for both racing distances. The sire, type of course, horse age and interaction between the type of course and track condition had a highly significant effect on best racing times. Estimates of heritability were 0.11 and 0.09 for $1200 \mathrm{~m}$ and $1800 \mathrm{~m}$, respectively. Rankings of sires' breeding values based on progeny records were quite different for the two racing distances. The Spearman rank correlation coefficient for these rankings was $0.350(P<0.05)$.
\end{abstract}

Key words: best racing times, environmental factors, heritability, sire evaluation, thoroughbred horse

\author{
J. Equine. Sci. \\ Vol. 5, No. 2 \\ pp 53-58
}

The performance of racehorses is generally measured by the time for a given distance, amount of earnings over a certain period and handicap weight or similar performance rating. Heritabilities of such traits have already been reviewed by some researchers $[3,5,6,16]$. The heritabilities of thoroughbred horses in Japan have been reported by Watanabe for times, earnings and performance rates [18-20]. In recent years, Moritsu et al. and Ueno et al. also reported the heritabilities for earnings and ranking index, respectively [7, 17].

Considering these performance traits, the time for a given distance is the only direct measure of speed and it is correlated with racing performance, but times recorded during a race are influenced by the sum of all circumstances associ-

This article was submitted April 14, 1994, and was accepted June 25, 1994.

*corresponding author. ated with that race. Many researchers have also reported that heritabilities for times are very low $[3,5,6,16,19]$. Regardless of these problems, however, racing time is the most frequently reported measure of racing performance. Moreover, Ojala et al. have reported that the best time in a year is the most useful measure for assessing sire breeding values based on progeny records of Finnish trotting horses [9]. We therefore think that accurate records accumulated on racing times would be very useful information for thoroughbred horse breeding, but little research has been reported on this subject in Japan.

The primary purpose of this study is to evaluate some fixed effects that influence best racing times of thoroughbred horses. The secondary objectives are to estimate heritabilities and to make genetic evaluations of sires on best racing times after some important fixed effects are adjusted by using the 
mixed model method [2, 13].

\section{Materials and Methods}

Racing records on thoroughbred horses kept by the Japan Racing Association were obtained from the electronic racing book edited in the summer of 1992 by TV Tokyo Station [15]. In this book, all individual racing records from 1985 to 1991 are edited. Records used in this study were horses' best times for the racing distances of $1200 \mathrm{~m}$ and 1800 $\mathrm{m}$. The best time for one horse is usually decided by a time achieved during a racing year or a lifetime. The best time in this study is the time achieved at the point of compilation for active horses. The data set was edited in such a way that each sire was required to have at least 20 progeny in each racing distance. The total numbers of sires and progeny are shown in Table 1.

Besides the random effect of the sire, the following factors were considered to be fixed effects that may influence a horse's best time. These factors were sex, training center, type of course, specific racetrack, horse age, track condition, racing season and load weight. The last two factors, however, were deleted, because a specific racetrack was correlated with the racing season and load weight was concentrated at a few weights. For example, Sapporo racing courses are open

Table 1. Distributional properties of best racing times by racing distance group for data used for statistical analysis

\begin{tabular}{lrr}
\hline & \multicolumn{2}{c}{ Distance } \\
\cline { 2 - 3 } \multicolumn{1}{c}{ Item } & $1200 \mathrm{~m}$ & $1800 \mathrm{~m}$ \\
\hline No. of sires & 34 & 34 \\
No. of female progeny & 770 & 551 \\
No. of male progeny & 716 & 969 \\
No. of total progeny & 1486 & 1520 \\
Mean & 72.83 & 113.13 \\
SD $^{\#}$ & 1.98 & 3.22 \\
CV(\%) & 2.72 & 2.84 \\
Minimum & \\
Maximum & \\
Skewness & 67.60 & 106.10 \\
Kurtosis $^{*}$ & 82.20 & 135.30 \\
& 0.43 & 0.68 \\
& 0.25 & 1.17 \\
\hline
\end{tabular}

Data were restricted to include only offspring of sires having at least 20 progeny. \#: Expressed in seconds. only during the summer, but Tokyo racing courses are not open during the summer, and 53 and 55 $\mathrm{kg}$ are the most common load weights for horses in Japan.

The following linear model was used to analyze the data:

$$
\mathrm{Y}_{i j k l m n o p}=\mu+\mathrm{S}_{i}+\mathrm{A}_{j}+\mathrm{B}_{k}+\mathrm{C}_{l}+\mathrm{D}_{m}+\mathrm{E}_{n}+\mathrm{F}_{o}+(\mathrm{CF})_{l o}+\mathrm{e}_{i j k l m n o p}
$$

where,

$\mathrm{Y}_{i j k l m n o p}:$ the individual observations for best racing times

$\mu$ : mean common to all observations

$\mathrm{S}_{i}:$ the random effect of the $i^{\text {th }}$ sire $(i=1, \ldots$, 34), $\operatorname{NIID}\left(0, \sigma_{\mathrm{s}}^{2}\right)$

all sires were assumed to be unrelated

$\mathrm{A}_{j}$ : the fixed effect of the $j^{\text {th }} \operatorname{sex}(j=1,2)$

$\mathrm{B}_{k}$ : the fixed effect of the $k^{\text {th }}$ training center $(k=1, \ldots, 3)$

$\mathrm{C}_{l}$ : the fixed effect of the $l^{\text {th }}$ type of course $(l=1,2)$

$\mathrm{D}_{m}$ : the fixed effect of the $m^{\text {th }}$ specific racetrack $(m=1, \ldots, 10)$

$\mathrm{E}_{n}$ : the fixed effect of the $n^{\text {th }}$ horse age $(n=1, \ldots, 3)$

$\mathrm{F}_{o}$ : the fixed effect of the $o^{\text {th }}$ track condition $(o=1, \ldots, 4)$

$(\mathrm{CF})_{l o}$ : the interaction between the $l^{\text {th }}$ type of course and $o^{\text {th }}$ track condition

$\mathrm{e}_{i j k l m n o p}:$ the random residual error effect, NIID $\left(\mathrm{O}, \sigma_{\mathrm{e}}^{2}\right)$

The least-squares analysis of variance was carried out by the GLM procedure of SAS [12]. Interactions between fixed effects in the model were tested and found to be non-significant, except $(\mathrm{CF})_{l o}$.

Variance components for sires and residuals were estimated by the VARCOMP procedure of SAS according to the REML method [12]. Estimates of heritability $\left(h^{2}\right)$ for the best racing times were calculated on the basis of the intraclass correlation of paternal half-sibs. Standard errors for heritabilities were computed by the method of Swiger et al. [14].

Predictions of sires' breeding values were done according to Henderson's best linear unbiased predictions (BLUP) method [2]. This calculation was carried out by using the MIXED procedure of SAS [13]. The expected progeny difference (EPD) of sires based on BLUP was one-half of the sires' 
breeding values.

\section{Results}

Distributional properties of best racing times for the two racing distances are shown in Table 1. The coefficients of variations (CV) were almost the same for both distances. When the distribution is completely normal, the values for skewness and kurtosis are zero. For each distance the distribution was skewed to the right and appeared more peaked than a normal distribution.

The results of analysis of variance for the seven factors for the two racing distances are shown in Table 2. The effect of sex for $1200 \mathrm{~m}$ and the effect of training center for $1800 \mathrm{~m}$ was not significant. The effects of other factors were significant for both distances. Above all, the effect of the sire was highly significant $(P<0.001)$ for both distances.

The least squares means and standard errors of the fixed effects for the two racing distances are shown in Table 3. The effects of the type of course and horse age obviously showed a constant tendency for both distances. The best racing times were shorter on turf courses than on dirt courses and the time was shorter under poor track conditions than under good track conditions for dirt courses as compared with turf courses. The best racing times tended to become shorter as the horses aged. Moreover, the best racing times were shorter for male horses than female horses for $1800 \mathrm{~m}$. The times were shorter at Ritto center than at the other center for $1200 \mathrm{~m}$. The effects of specific racetracks differed for the two racing distances.

Estimates of heritability and its standard error for best racing time are presented in Table 4 for the two racing distances. Heritabilities were 0.11 and 0.09 for $1200 \mathrm{~m}$ and $1800 \mathrm{~m}$, respectively. Estimated heritability was slightly greater for 1200 $\mathrm{m}$ than $1800 \mathrm{~m}$. Standard errors of heritability were very small and showed almost the same value for both distances.

The EPD of sires based on BLUP was one-half of the sire's breeding values. The EPD of sires was expressed in seconds. The correlation of a sire's EPDs estimated by each racing distance is shown in Figure 1. There was no linear trend between the two EPD values for each sire, and the Spearman rank correlation coefficient was $0.350(P<0.05)$, which is quite low. Large differences occurred between the rankings of sires estimated for each racing distance.

\section{Discussion}

Thoroughbred horse races of the Japan Racing Association are held at ten specific racetracks throughout the country according to an annual schedule. Thoroughbred horse races range from $1000 \mathrm{~m}$ to $3600 \mathrm{~m}$ on turf or dirt courses. The racing distances reported in this study were 1200 $\mathrm{m}$ and $1800 \mathrm{~m}$. These two distances are raced more frequently than the others, the former being called a short distance and the latter a middle distance.

Except for the obvious differences in means and

Table 2. Least-squares analysis of variance for best racing times by racing distance

\begin{tabular}{lrcrc}
\hline & \multicolumn{2}{c}{$1200 \mathrm{~m}$} & \multicolumn{2}{c}{$1800 \mathrm{~m}$} \\
\cline { 2 - 5 } Source of variation & d.f. & M.S. & d.f. & M.S. \\
\hline Sire & 33 & $4.16^{* * *}$ & 33 & $7.05^{* * *}$ \\
Sex & 1 & 1.14 & 1 & $52.47^{* * *}$ \\
Training center & 2 & $10.60^{* *}$ & 2 & 7.74 \\
Turf of Dirt-course (T) & 1 & $484.03^{* * *}$ & 1 & $1293.45^{* * *}$ \\
Specific racetrack & 9 & $35.97^{* * *}$ & 9 & $67.82^{* * *}$ \\
Horse age & 2 & $184.86^{* * *}$ & 2 & $412.94^{* * *}$ \\
Track condition (C) & 3 & $5.36^{*}$ & 3 & $42.29^{* * *}$ \\
T $\times$ C & 3 & $73.35^{* * *}$ & 3 & $200.64^{* * *}$ \\
Residuals & 1431 & 1.72 & 1465 & 3.61 \\
\hline
\end{tabular}

$* P<0.05, * * P<0.01, * * * P<0.001$, respectively. 
Table 3. Least squares means and standard errors of the fixed effects for best racing times by racing distance

\begin{tabular}{|c|c|c|c|c|}
\hline \multirow{2}{*}{$\begin{array}{l}\text { Fixed effects } \\
\text { with the levels }\end{array}$} & \multicolumn{2}{|c|}{$1200 \mathrm{~m}$} & \multicolumn{2}{|l|}{$1800 \mathrm{~m}$} \\
\hline & L.S. Means ${ }^{\#}$ & $\mathrm{SE}^{\#}$ & L.S. Means ${ }^{\#}$ & $\mathrm{SE}^{\#}$ \\
\hline \multicolumn{5}{|l|}{ Sex } \\
\hline female & $73.26^{\mathrm{a}}$ & 0.07 & $114.13^{\mathrm{a}}$ & 0.14 \\
\hline male & $73.21^{\mathrm{a}}$ & 0.07 & $113.73^{\mathrm{b}}$ & 0.14 \\
\hline \multicolumn{5}{|l|}{ Training center } \\
\hline Miho-kita & $73.44^{\mathrm{a}}$ & 0.10 & $113.96^{\mathrm{a}}$ & 0.17 \\
\hline Miho-minami & $73.29^{\mathrm{a}}$ & 0.10 & $114.11^{\mathrm{a}}$ & 0.17 \\
\hline Ritto & $72.97^{\mathrm{b}}$ & 0.08 & $113.71^{\mathrm{a}}$ & 0.15 \\
\hline \multicolumn{5}{|l|}{ Type of course } \\
\hline $\operatorname{dirt}(\mathrm{D})$ & $74.25^{\mathrm{a}}$ & 0.09 & $115.75^{\mathrm{a}}$ & 0.17 \\
\hline turf $(\mathrm{T})$ & $72.21^{\mathrm{b}}$ & 0.09 & $112.11^{\mathrm{b}}$ & 0.15 \\
\hline \multicolumn{5}{|l|}{ Specific racetrack } \\
\hline Chukyo & $72.94^{\mathrm{a}}$ & 0.16 & $113.39^{\mathrm{a}}$ & 0.22 \\
\hline Fukushima & $73.13^{\mathrm{ab}}$ & 0.14 & $114.30^{\mathrm{b}}$ & 0.22 \\
\hline Hakodate & $73.61^{\mathrm{b}}$ & 0.16 & $114.00^{\mathrm{abc}}$ & 0.32 \\
\hline Hanshin & $74.41^{\mathrm{c}}$ & 0.16 & $114.55^{\mathrm{bd}}$ & 0.30 \\
\hline Kokura & $73.32^{\text {bd }}$ & 0.16 & $115.25^{\mathrm{de}}$ & 0.24 \\
\hline Kyoto & $73.17^{\mathrm{ad}}$ & 0.12 & $113.19^{\text {af }}$ & 0.18 \\
\hline Nakayama & $72.36^{\mathrm{e}}$ & 0.08 & $114.47^{\mathrm{bd}}$ & 0.14 \\
\hline Niigata & $73.43^{\text {bdf }}$ & 0.15 & $113.28^{\mathrm{ac}}$ & 0.33 \\
\hline Sapporo & $73.53^{\text {bdg }}$ & 0.16 & $113.83^{\text {abcdf }}$ & $\begin{array}{l}0.50 \\
0.49\end{array}$ \\
\hline Tokyo & $72.44^{\mathrm{e}}$ & 0.18 & $113.01^{\mathrm{ag}}$ & 0.20 \\
\hline \multicolumn{5}{|l|}{ Horse age } \\
\hline 3 -year-olds & $73.97^{\mathrm{a}}$ & 0.09 & $115.25^{\mathrm{a}}$ & 0.24 \\
\hline 4-year-olds & $73.39^{\mathrm{b}}$ & 0.07 & $114.07^{\mathrm{b}}$ & 0.11 \\
\hline 5 -year-olds $\leqq$ & $72.35^{\mathrm{c}}$ & 0.10 & $112.46^{\mathrm{c}}$ & 0.14 \\
\hline \multicolumn{5}{|l|}{ Track condition } \\
\hline D-good & $74.87^{\mathrm{a}}$ & 0.10 & $116.76^{\mathrm{a}}$ & 0.19 \\
\hline D-somewhat poor & $74.28^{\mathrm{b}}$ & 0.14 & $115.64^{\mathrm{b}}$ & 0.23 \\
\hline D-poor & $73.96^{\mathrm{bc}}$ & 0.14 & $115.06^{c}$ & 0.23 \\
\hline D-bad & $73.90^{\mathrm{c}}$ & 0.16 & $115.53^{\mathrm{bc}}$ & 0.24 \\
\hline T-good & $71.53^{\mathrm{d}}$ & 0.07 & $111.03^{\mathrm{d}}$ & 0.11 \\
\hline T-somewhat poor & $71.81^{\mathrm{d}}$ & 0.15 & $111.65^{\mathrm{e}}$ & 0.22 \\
\hline $\mathrm{T}$-poor & $72.34^{\mathrm{e}}$ & 0.17 & $111.82^{\mathrm{e}}$ & 0.30 \\
\hline T-bad & $73.17^{\mathrm{f}}$ & 0.23 & $113.92^{\mathrm{f}}$ & 0.30 \\
\hline
\end{tabular}

\#: Expressed in seconds.

L.S. Means within a fixed effect with no common superscrips differ significantly $(P<0.05)$ by using PDIFF option in SAS.

Table 4. Estimates of heritability and standard errors (SE) for best racing times by racing distance

\begin{tabular}{lcc}
\hline Distance & Heritability $^{\#}$ & SE \\
\hline $1200 \mathrm{~m}$ & 0.11 & 0.03 \\
$1800 \mathrm{~m}$ & 0.09 & 0.02 \\
\hline
\end{tabular}

\#: Estimates of heritability were calculated based on the intraclass correlation of paternal half-sibs. variances, the distributions of best racing times for each distance were similar in shape to those reported for Quarter horses by Buttram et al. [1]. In the case of statistical analysis by linear models and the BLUP method, a dependent variable used in analysis is generally assumed to be a normal distribution. It can be said that racing time has a nearly normal distribution and is a better measurement with which to do a statistical analysis than horse earnings that differ greatly from a normal distribution, as Moritsu et al. reported [7]. 


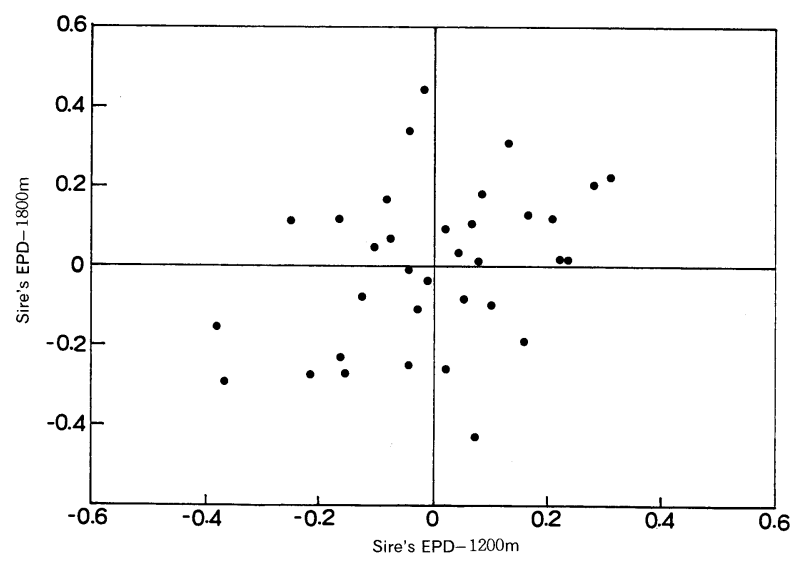

Fig. 1. Correlation of sire's breeding values based on the progeny's best racing times at two different racing distances. The expected progeny differences (EPD) of 34 sires were calculated by the BLUP method. The sire's breeding value can be obtained by doubling the sire's EPD.

When the data for best racing times have been accumulated on an annual basis, it can be expected that many factors have influenced each record. As shown in Table 2, almost all the factors included in the linear model were statistically significant in this study, but the results of the analysis were slightly different for short and middle race distances. The details of such factors were shown by using the least square means in Table 3 . The best racing times are shorter for male horses than for female horses for the middle distance. The time is shorter for turf courses than dirt courses, and shorter for adult horses than younger horses. The times for turf courses are shorter under good track conditions than under bad track conditions, but the times for dirt courses are longer under poor track conditions than under good track conditions. We think that these trends would be acceptable results for persons concerned with horse racing, but we cannot find appropriate explanations for the training center and specific racetrack factors. As far as we know, the Ritto Training Center makes use of a sloping training track. It is also known that each specific racetrack has a characteristic construction. Moreover, a horseman generally believes that an interaction between the sire and the type of course is an important factor affecting the racing time. Oki has also reported that the effect of the interaction between the birthplace of the sire and the type of course was determined for the racing times of thoroughbred horses [10]. Howev- er, in this study, the effect of interaction between the sire and the type of course was not statistically significant as a result of using the previous liner model.

To estimate heritability for the best racing time, it is necessary to make allowance for known sources of environmental variation. Sire and residual variance components were calculated with the previous liner model including the seven fixed effects. For this calculation, the method of restricted maximum likelihood (REML) was used because it has the most desirable statistical properties for most animal breeding problems [11]. As shown in Table 4, estimates of heritabilities for best racing time were 0.11 and 0.09 for $1200 \mathrm{~m}$ and $1800 \mathrm{~m}$, respectively. In the literature, many researchers have reported that estimates of heritabilities for racing time are relatively low for thoroughbred horses [3, 5, 6, 16]. And in Japan Watanabe has reported that the half-sib heritability estimate was 0.116 for adjusted times of 500 four-year-olds who placed first, second or third in Japanese races from 1964 to 1966, given the common base of $1600 \mathrm{~m}$, normal turf conditions, and a 50-55 kg handicap [19]. The result of this study was close to those of previous reports, despite the difference between the methods of analysis.

An EPD of sires based on BLUP was one-half of the sire's breeding value. The correlation of a sire's EPDs estimated for $1200 \mathrm{~m}$ and $1800 \mathrm{~m}$ is shown in Figure 1. No linear trend between both of the sire's EPDs was observed. Moreover, the Spearman rank correlation coefficient was 0.350 , which is very low. Thoroughbred horses are generally divided into three types by aptitude for the race distance: sprinter $(<1200 \mathrm{~m})$, miler $(1600 \mathrm{~m})$ and stayer $(>2200 \mathrm{~m})$. It is considered that the body types for these three distances differ from each other. In this study, the distances of $1200 \mathrm{~m}$ and $1800 \mathrm{~m}$ are suitable for sprinters and milers, respectively. Moritsu et al. have also reported that the body weight of thoroughbred horses is more heritable than some racing performances [8]. We think that the difference between sires' rankings for the two racing distances can be explained by the above reasons, but it is interesting to note that five of the 34 sires show higher EPD values for both racing distances.

In this study, all sires were assumed to be unrelated, but such was not a valid assumption. As 
shown by Henderson, additive relationships among the male ancestors of the progeny will be implemented in the sire evaluation procedure [2]. It was known that this would increase the accuracy of evaluations for sires having small progeny groups. Klemetsdal has stated that the BLUP method and the animal model have become the standard method for genetic evaluation in horse breeding [4]. According to his report, a sire model, as in this study, has been adopted for progeny testing of the standardbred trotter in Sweden and Germany, and the animal model will in the near future be used routinely in predicting the breeding value of thoroughbreds in France, in NorthSwedish trotters and in Norwegian trotters. We think that a suitable application of the BLUP method will be required for thoroughbred horse breeding in Japan.

\section{References}

1. Buttram, S.T., Willham, R.L., Wilson, D.E., and Heird, J.C. 1988. Genetics of racing performance in the American Quarter Horse 1. Description of the data. J. Anim. Sci. 66: 2791-2799.

2. Henderson, C.R. 1973. Sire evaluation and Genetic trend. Proc. Anim. Breeding and Genetics Symposium in Honor of Dr. J.L. Lush, 10-41, ASAS and ADSA, Champaign, Illinois.

3. Hintz, R.L. 1980. Genetics of performance in the horse. J. Anim. Sci. 51: 582-594.

4. Klemetsdal, G. 1990. Breeding for performance in horses-a review. In: Proc. of the 4th World Congress on Genetics Applied to Livestock Production, 184-193, Edinburgh, UK.

5. Langlois, B. 1980. Heritability of racing ability in thoroughbreds-a review. Livest. Prod. Sci. 7: 591-605.

6. More O'Ferrall, G.J., and Cunningham, E.P. 1974. Heritability of racing performance in thoroughbred horses. Livest. Prod. Sci. 1: 87-97.

7. Moritsu, Y., Kimura, Y., and Ichikawa, S. 1991.
Heritability of annual earnings in Thoroughbreds. Jpn. J. Equine Sci. 2: 11-16.

8. Moritsu, Y., Ohtsuka, T., and Ichikawa, S. 1994. Heritability of body weight for 3-year-old Thoroughbred horses (In press).

9. Ojala, M., Van Vleck, L.D., and Quass, R.L. 1987. Factors influencing best annual racing time in Finnish horses. J. Anim. Sci. 64: 109-116.

10. Oki, H. 1984. Genetic study of racing performance in the Thoroughbred horse 1. Differences in racing times between turf and dirt-course. Jap. J. Zootech. Sci. 55: 215-219.

11. Patterson, H.D., and Thompson, R. 1971. Recovery of interblock information when block sizes are unequal. Biometrika 58: 545-554.

12. SAS Inst. Inc. 1989. SAS/STAT User's Guide volume 2 GLM-VARCOMP (Release 6.04), SAS Inst. Inc., Cary, NC.

13. SAS Inst. Inc. 1992. SAS Tech. Rep. P-229. SAS/STAT Software, Changes and Enhancements (Release 6.07). pp. 289-366, SAS Inst. Inc., Cary, NC.

14. Swiger, L.A., Harvey, W.R., Everson, D.O., and Gregory, K.E. 1964. The variance of intraclass correlation involving groups with one observation. Biometrics 20: 818-826.

15. TV Tokyo Station. 1992. Electronic racing book of horse racing records of the Japan Racing Association. '92-summer, Yumakkusu Inc., Tokyo.

16. Tolley, E.A., Notter, D.R., and Marlowe, T.J. 1985. A review of the inheritance of racing performance in horses. Anim. Breed. Abstr. 53: 163-185.

17. Ueno, T., Motoyoshi, S., and Tanaka, R. 1991. Presumption of heritability for racing performance of Thoroughbreds. Bull Nippon Vet. Anim. Sci. Univ. 40: 29-33.

18. Watanabe, Y., Shimoiizaka, T., and Sato, K. 1965. An analysis of the racing performances of thoroughbreds in Japan. Res. Bull. Livestock Farm, Fac. Agr. Hokkaido Univ. 1: 1-7.

19. Watanabe, Y. 1969. Timing as a measure of selection in Thoroughbred breeding. Jap. J. Zootech. Sci. 40: 271-276.

20. Watanabe, Y. 1974. Performance rates of thoroughbreds as a criterion of racing ability. Jap. J. Zootech. Sci. 45: 408-411. 